Meta

Journal des traducteurs

Translators' Journal

\title{
El lenguaje de las revistas femeninas españolas: la (no) traducción como ideología
}

\section{Carmen África Vidal Claramonte}

Volume 57, numéro 4, décembre 2012

Journalisme et traduction

Journalism and Translation

URI : https://id.erudit.org/iderudit/1021231ar

DOI : https://doi.org/10.7202/1021231ar

Aller au sommaire du numéro

Éditeur(s)

Les Presses de l’Université de Montréal

ISSN

0026-0452 (imprimé)

1492-1421 (numérique)

Découvrir la revue

Citer cet article

Vidal Claramonte, M. C. Á. (2012). El lenguaje de las revistas femeninas españolas: la (no) traducción como ideología. Meta, 57(4), 1029-1045. https://doi.org/10.7202/1021231ar
Résumé de l'article

Le langage est un phénomène typiquement humain : c'est principalement pour cette raison qu'il est associé au pouvoir. Lié à la vie par son essence, il est un phénomène par lequel il nous est donné de grandir, d'établir des relations interpersonnelles, de négocier, d'aimer et de haïr. Le langage et l'utilisation que nous en faisons sont particulièrement intéressants à une époque comme la nôtre, caractérisée par la globalisation et la prolifération de discours prônant l'homogénéisation. L’objectif du présent article est d'analyser les particularités langagières des traductions de textes du domaine de la mode et de la commercialisation de produits dans des revues féminines en espagnol. Dans ce type de texte, on remarque que bon nombre de mots anglais ou français demeurent intraduits. Or, en réalité, ces mots intraduits sont déjà des traductions, car le fait de les lire en anglais ou en français suscite chez le lectorat des réactions particulières qu'il n'aurait pas éprouvées si ces mots avaient été traduits, en castillan dans ce cas.
Ce document est protégé par la loi sur le droit d'auteur. L’utilisation des services d’Érudit (y compris la reproduction) est assujettie à sa politique d'utilisation que vous pouvez consulter en ligne.

https://apropos.erudit.org/fr/usagers/politique-dutilisation/ 


\title{
El lenguaje de las revistas femeninas españolas: la (no) traducción como ideología:
}

\author{
M. CARMEN ÁFRICA VIDAL CLARAMONTE \\ Universidad de Salamanca, Salamanca, España \\ africa@usal.es
}

\begin{abstract}
RÉSUMÉ
Le langage est un phénomène typiquement humain: c'est principalement pour cette raison qu'il est associé au pouvoir. Lié à la vie par son essence, il est un phénomène par lequel il nous est donné de grandir, d'établir des relations interpersonnelles, de négocier, d'aimer et de haïr. Le langage et l'utilisation que nous en faisons sont particulièrement intéressants à une époque comme la nôtre, caractérisée par la globalisation et la prolifération de discours prônant l'homogénéisation. L'objectif du présent article est d'analyser les particularités langagières des traductions de textes du domaine de la mode et de la commercialisation de produits dans des revues féminines en espagnol. Dans ce type de texte, on remarque que bon nombre de mots anglais ou français demeurent intraduits. Or, en réalité, ces mots intraduits sont déjà des traductions, car le fait de les lire en anglais ou en français suscite chez le lectorat des réactions particulières qu'il n'aurait pas éprouvées si ces mots avaient été traduits, en castillan dans ce cas.
\end{abstract}

\section{ABSTRACT}

Language is a typically human phenomenon and, for that reason, essentially linked to the desire for Power; essentially linked to life, it is the phenomenon we grow up with, we use to create relationships with others, to negotiate, to love and to hate. Language, and the use we make of language, is particularly interesting at a moment in time like the present, characterised by globalisation and the proliferation of homogenizing discourses. The aim of this essay is to consider the peculiar uses of language in the translation of texts related to the world of fashion and marketing of products in women's magazines. In these texts many words are not translated, we find frequent uses of English and French. These untranslated words are already translations, because the fact that they remain in English or French provokes sensations we would not have if they had been transmitted to us, in this case, in Spanish.

\section{MOTS-CLÉS/KEYWORDS}

globalisation, revues féminines, mythe, langage, idéologie

globalisation, women's magazines, myth, language, ideology

Abro una revista de Moda: me encuentro con dos vestidos distintos. El primero es el que me presentan fotografiado o dibujado, es un vestido-imagen. El segundo es ese mismo vestido, pero esta vez descrito, transformado en lenguaje; ese vestido fotografiado de la derecha se convierte a la izquierda en: cinturón de piel por encima del talle, con una rosa prendida, sobre un fluido vestido de shetland; es un vestido escrito. En principio ambos remiten a la misma realidad (ese vestido que la mujer llevaba ese día), pero en cambio no tienen la misma estructura, porque no están hechos con los mismos materiales y, por lo tanto, esos materiales no mantienen las mismas relaciones entre sí: en uno los materiales son formas, líneas, superficies, colores y su relación es espacial, mientras que en el otro son palabras y la relación, si no lógica, es cuando menos sintáctica; la primera estructura es plástica, la 
segunda, verbal. ¿Quiere esto decir que cada una de esas estructuras se confunde por entero con el sistema general del que emana, el vestido-imagen con la fotografía y el vestido escrito con el lenguaje? En absoluto: la fotografía de Moda no es cualquier fotografía... conlleva unidades y reglas específicas; constituye, dentro de la comunicación fotográfica, un lenguaje particular, poseedor sin duda de léxico y sintaxis propios, de "giros" propios, prohibidos o recomendados.

(Barthes 1967/2003: 19-20)

\section{1. ¿Qué hay de peligroso en el hecho de que la gente escriba?}

El 2 de diciembre de 1970 Michel Foucault pronunció en el Collège de France la lección inaugural, titulada El orden del discurso. El filósofo articula toda su conferencia en torno a una pregunta que siempre me ha parecido apasionante: “QQué hay de peligroso en el hecho de que la gente hable?" Es evidente que la pregunta no es nueva. Desde los sofistas, el ser humano se ha planteado qué es hablar y qué consecuencias tiene. Quién puede hablar y quién es/debe ser silenciado. El lenguaje es un fenómeno típicamente humano, y por eso esencialmente ligado al deseo de Poder; esencialmente ligado a la vida, es el fenómeno con el que crecemos, nos relacionamos, negociamos, amamos y odiamos. De ahí que la pregunta de Foucault resulte especialmente interesante en un momento histórico como el nuestro, caracterizado por la globalización y la proliferación de discursos homogeneizadores.

Recordé la pregunta de Foucault cuando hace unos meses me enteré de que una empresa estaba buscando traductores especializados en textos relacionados con el mundo de la moda y la publicidad de productos destinados a las mujeres. El mecenas solicitaba un traductor que conociese bien ese mundo y que supiese qué y cuándo se debía traducir. La petición, sin duda algo sorprendente en un primer momento (¿no se nos paga a los traductores para traducirlo todo?), no lo es si pensamos que en el mundo de la moda el lenguaje se utiliza de una manera cuando menos peculiar, sobre todo en España, país donde en muchas ocasiones se dejan sin traducir muchas palabras precisamente por el efecto que esas no-traducciones crean en el lector de la cultura meta. Por ejemplo, en las versiones españolas de revistas como Vogue, Marie Claire o Cosmopolitan, por citar sólo algunas muy conocidas, son constantes las palabras que encontramos en inglés y francés: frases como Todas somos beautiful, Es un must de esta temporada, o palabras como glamour, sexy, etc. son frecuentes en portadas y artículos interiores. Este será precisamente el objeto de estudio de este ensayo. Lo que intentaré demostrar en estas páginas es que esas palabras sin traducir son una traducción, porque el hecho de que se dejen intencionadamente en inglés o francés provoca unas sensaciones que no tendríamos si nos las hubiesen hecho llegar en español.

Como es lógico, determinadas formas de actuar del traductor de ese tipo de textos responden a unas exigencias de su mecenas que a su vez tienen que ver con el mercantilismo homogeneizador que ha traído consigo la globalización. En este sentido, un excelente ejemplo es precisamente la prensa femenina, que, hoy más que nunca, favorece la difusión social a gran escala de unos determinados modelos estéticos, y, por lo tanto, su influencia es enorme: poco a poco las representaciones y los mensajes ligados a la belleza femenina han dejado de ser signos excepcionales para invadir la vida cotidiana de las mujeres de toda condición social: 
Jamás civilización alguna produjo y difundió tantos discursos relativos a los cuidados de belleza... Con el florecimiento de la prensa femenina de gran tirada aparece una nueva manera de hablar del aspecto físico femenino. Hasta entonces los discursos sobre la belleza femenina eran o bien obra de poetas, novelistas y médicos, o bien secretos cuchicheados entre mujeres. A partir del siglo XX, las revistas femeninas se convierten en los vectores principales de difusión social de las técnicas estéticas. Al dirigirse a un gran público, surge una nueva retórica que conjuga belleza y consumo, adopta un tono eufórico o humorístico, un lenguaje directo y dinámico, en ocasiones próximo al lenguaje publicitario. A lo cual se suma un trabajo de escenificación de los discursos, una presentación estética del texto y de las imágenes que diferencia a la prensa femenina de las demás publicaciones. (Lipovetsky 1997/1999: 143-144)

Efectivamente, en este tipo de revistas se cuida hasta el más mínimo detalle, pero muy especialmente el lenguaje, o mejor dicho los lenguajes, los colores, las imágenes, porque todo, absolutamente todo, significa. En este contexto, la utilización de los signos dista mucho de ser inocente: los responsables de esas publicaciones saben que cuanto se vende en ellas, desde el cuerpo de la mujer hasta todo tipo de productos cosméticos, se vende únicamente a través de diversos sistemas semióticos, que son sus estrategias mercantilistas más útiles; y esos sistemas semióticos no incluyen solamente las palabras, por supuesto, sino también las imágenes, los colores, la tipografía, etc. (véase Martín Aguado y Armentia Vizuete 1995; Pendones de Pedro 1999; Lallana 2000). Todo vende y todo significa. Por eso, al contratar a traductores para ese tipo de revistas, lo hacen con sumo cuidado, pues necesitan que sean personas muy conscientes de la clase de mundo al que se van a incorporar. (Casi) todas las mujeres occidentales aspiramos a ser como y a parecernos a unos cánones que se nos han ido imponiendo, eso sí, muy sutilmente, a través de unos códigos semióticos que, como ya he apuntado, no solamente incluyen el lingüístico sino también, y quizá sobre todo, la imagen, y que siguen unas estrategias muy bien pensadas.

La globalización ha transformado las formas epistemológicas de acercarse a la existencia cotidiana y ha alterado los discursos y experiencias particulares. Esto es así en parte porque, gracias a las nuevas tecnologías, se ha facilitado el acercamiento entre las sociedades y en parte también porque, en la medida en que nos hallamos ante una globalización desigual que tiene como rasero homogeneizador el que imponen las potencias mundiales, se difumina la percepción misma de la diversidad, al tiempo que se acrecientan los abismos y malentendidos interculturales, dado que en realidad es falso que hoy en día todo el mundo tenga acceso a la información libremente: en el fondo, son pocos quienes acceden realmente a los verdaderos recursos y menos todavía quienes saben utilizarlos críticamente.

En este contexto, el lenguaje nunca es neutro, y el acto de elegir una palabra y no otra puede tener consecuencias muy importantes en el texto meta. Así que, volviendo a Foucault, es muy importante darnos cuenta de qué hay de peligroso en el hecho de que la gente (re)escriba y traduzca (o no) unos textos cuyo propósito final es globalizar una manera (occidental) de ver a la mujer y primar lo homogéneo sobre lo particular, lo global frente a lo local, mediante una utilización muy concreta del lenguaje. El empleo de palabras en inglés y en francés en las revistas femeninas españolas es una manera tremendamente manipuladora de utilizar el lenguaje, por eso creo que es interesante preguntarse qué consecuencias ideológicas tiene ese hecho de mezclar lenguas que no son ni mucho menos simétricas respecto a la española. Mis puntos de partida para la fundamentación teórica serán el concepto de lo «natural» 
de Roland Barthes y el de Poder (en relación con las tecnologías del yo) de Michel Foucault.

\section{Las revistas femeninas}

En Language and Symbolic Power, Pierre Bourdieu (1991) advierte que el lenguaje es más un instrumento de poder que de comunicación. Para hacer llegar sus mensajes, las revistas femeninas utilizan diversos tipos de lenguaje (tal vez la imagen sea el más atractivo de todos en este contexto). Desde su nacimiento, las revistas femeninas (paradójicamente, o quizá lógicamente, dirigidas y pensadas por mujeres) han ido construyendo un ideal de mujer mediante la inscripción en él de los significados sociales impuestos; y todo ello se ha conseguido al entender el cuerpo femenino como un texto que se iba configurando a través de los textos que lo acompañaban, textos que van dirigidos a la creación de una identidad controlada y estable que se adapte a un sistema regulado desde el patriarcado y que no hace más que perpetuar determinados tipos de representación que dan lugar a construcciones ficticias de la identidad (Stoll 1994; 1997).

Cierto es que hay algunos estudios (Frazer 1987; Hermes 1995; Lipovetsky 1997/1999) que consideran que la mujer es crítica con la ideología que le va transmitiendo la revista, que no se la toma en absoluto en serio y es más bien un pasatiempo para relajarse (Hermes 1995), y que por eso se leen de una manera diferente a un ensayo o a un libro (Radner 1995; McCracken 1993); o que las revistas femeninas en realidad sirven en cierta manera para difundir algunas ideas feministas (McRobbie 1999) ${ }^{1}$. Sin embargo, subsisten como mensajes subliminales conceptos que distan mucho de ser feministas y que contrastan, en mi opinión, con la idea de una mujer que ha alcanzado la verdadera libertad, según intentaré demostrar más adelante. Los estudios a favor de las revistas femeninas advierten que la mujer muchas veces se ríe de esos consejos o que los entiende con sentido crítico o incluso irónicamente. Tal vez sea cierto que en muchos casos la influencia de estas revistas no es exclusiva, pero decir que es inexistente y que sus lectoras no se ven en absoluto afectadas por lo que ven y por lo que leen sería, a mi modo de ver, bastante ingenuo ${ }^{2}$.

Resulta cuando menos paradójico que en un siglo en el que la mujer parecía haber conseguido la libertad sexual y el control de su propio cuerpo haya todavía ámbitos como el de las revistas femeninas, escritas mayoritariamente por mujeres, donde tantas expectativas se mantienen sobre los cuerpos de las mujeres, de los cuales se espera que se adapten a unos cánones homogeneizadores, impuestos por la globalización de valores occidentales, las «monoglot views» contra las que nos advertía Cronin (2003) o la «convergence in social systems» a la que hace referencia Schäffner (2000). Por lo tanto, en este ensayo me sitúo mucho más en la línea de Adorno (1991), cuando habla del enorme poder que ejercen los medios de comunicación de masas en la población ${ }^{3}$, que en la de John Fiske, el otro gran nombre en estas cuestiones, que asegura que es el público, y no los medios, quien tiene en realidad el poder.

Mi punto de partida es, pues, que ninguno de los lenguajes utilizados por este tipo de revistas (imágenes, colores, palabras, tipografía, etc.) es neutro ni inocente; no son «languages as mirrors, that reflect how things are in their descriptions, representations and accounts», por decirlo con Potter (1996/2008: 97-98), sino «languages as construction yards [...] languages that construct the world, or at least versions of 
the world [...] The world is constituted in one way or another as people talk it, write, argue it» (Potter 1996/2008: 98). El lenguaje de estas revistas intenta apelar a los hechos, a lo que es, mediante descripciones que parecen realistas, neutrales, espejos de la realidad. Pero, sobre todo a la hora de traducir, hay que tener presente lo que ya hace tiempo Eco denominara "criterio de interpretancia»: que el signo no sólo requiere que exista una sustitución sino que trae consigo una interpretación, porque el signo nos hace recorrer todo el círculo de la semiosis, porque cualquier signo siempre nos abre «a algo distinto. No existe interpretante alguno que, al adecuar el signo que interpreta, no desplace, al menos mínimamente, sus límites» (Eco 1984/1990: 72), sin que ello se entienda como una semiosis ilimitada ni una «interpretabilidad descontrolada» (Eco 1984/1990: 14). El traductor deberá darse cuenta de cómo y con qué fin se producen estas estrategias.

Es evidente que con el paso del tiempo la representación de las mujeres en las revistas femeninas ha cambiado muchísimo (véase Seoane y Sáiz 1988; Gallego Ayala 1990; Lipovetsky 1997/1999; Hinojosa Mellado 2007). Especialmente durante los años cincuenta del siglo pasado, las revistas daban consejos dirigidos a ser una buena esposa, una excelente ama de casa y una mejor madre. Pero sobre todo se trataba de impresionar al marido, que era la figura en torno a la cual giraba toda la vida doméstica, teniendo la casa limpísima y sabiendo utilizar el último artilugio en la cocina. La mejor descripción de esta «happy housewife heroine» la encontramos, en mi opinión, en el libro, ya clásico, de Betty Friedan titulado The Feminine Mystique:

The image of woman that emerges from this big, pretty magazine is young and frivolous, almost childlike; fluffy and feminine; passive; gaily content in a world of bedroom and kitchen, sex, babies, and home. The magazine surely does not leave out sex; the only goal a woman is permitted is the pursuit of a man. It is crammed full of food, clothing, cosmetics, furniture, and the physical bodies of young women, but where is the world of thought and ideas, the life of the mind and spirit? (Friedan 1963: 32)

Las revistas iban así construyendo unas identidades alejadas de las mujeres con carreras universitarias o educación superior, porque todo eso las masculinizaba y tenía consecuencias muy negativas para el buen funcionamiento del hogar: supondría no atender correctamente a los hijos y sobre todo al esposo. Cierto es que, aunque con alguna dificultad y no demasiada premura, las revistas femeninas fueron adaptándose a los inevitables cambios sociales relacionados con la liberación de la mujer. Uno de los ejemplos más significativos tal vez sea la aparición de la revista $M s$, en Nueva York en 1972, y que, inspirada por el movimiento de liberación de la mujer, hablaba de política, de los logros de las mujeres fuera del hogar o de cuestiones feministas. Sin embargo, esto fue un tímido comienzo, porque la revista no vendía tantos ejemplares como las más tradicionales y porque, como observa Barbara Phillips,

the "heroines" featured in $M s$ 's articles were not women who had become millionaires - the traditional model by which American men would be judged a success - but rather were women who had helped to bring important political, social or cultural changes. Therefore, it could be argued [...] that women were still being praised for their selfless virtue - a "feminine" trait. This seems unduly picky though, especially as a magazine which simply applied so-called 'male' values to women would be criticised too, for not challenging the accepted models of what makes a person successful or important. (Phillips 1978, citado por Gauntlett 2008: 56) 
A pesar de todo, las revistas, su lenguaje y sus imágenes, fueron cambiando y adaptándose a las nuevas realidades sociales. Tal vez la más atrevida, aún hoy en día, fuese Cosmopolitan, que en su versión más contemporánea fue lanzada en Estados Unidos en 1964 por Helen Gurley Brown. La chica cosmo se define como independiente, sexy:

More of them than ever before had gone away to college, and often on to the pill, and, with high expectations of a world at their feet they were set, if nothing else, on ensuring they didn't have to forsake womanly delights, as their spinsterly and not to be envied schoolteachers had, in order to take a public place in the world. (Winship 1987: 107)

Es verdad que algunas como Marie Claire o Telva (en España) no dudan en abordar, desde perspectivas ideológicas diferentes, temas algo más profundos, como el de la liberación de la mujer o el aborto, en algunos textos, editoriales, artículos de opinión, etc.; e incluso en algunos números de las revistas se pueden leer entrevistas con altas ejecutivas que han triunfado en unos mundos reservados a los hombres. Tal vez por eso Joana Bonet, directora de Marie Claire en España, afirmaba en el número de octubre de 2010 que

El ADN de Marie Claire parte de una mujer que quiere estar informada de lo que acontece en el mundo, que busca más allá de las tendencias o los pensados de la temporada en una revista femenina y que toma un papel activo en el mundo que vivimos ... la mujer que lee Marie Claire ha encontrado ese algo especial que caracteriza no sólo su look, sino su forma de estar en el mundo. (Bonet 2010: 2)

Pero, ¿de verdad han cambiado tanto las cosas en el mundo de las revistas femeninas? En mi opinión, hay todavía un largo camino por recorrer, porque acaso los cambios sean más bien de cara a la galería, especialmente en revistas como Cosmopolitan. Y sobre todo porque lo que en general la mujer va buscando en esas revistas no es precisamente filosofía ni metafísica: la verdad es que resulta difícil pensar que determinadas lecturas sean edificantes para la configuración de la identidad femenina cuando los títulos de los artículos son del tipo Encuentra a tu hombre, Accesorízate, Hombres que inspiran.

En la actualidad existen muchísimas revistas para mujeres, y cada una tiene un sesgo algo diferente. En España, por ejemplo, hay revistas femeninas más de derechas (Telva, por citar una muy conocida) y otras más de izquierdas (Marie Claire, por ejemplo). A pesar de eso, todas tienen cosas en común, tal vez porque, igual que la globalización homogeneiza valores y formas de ser y parecer (tal y como hemos visto en el apartado anterior), también homogeneiza el lenguaje: «spreads, particular ways of using language (for example in politics, business, advertising) across national, cultural and linguistic boundaries» (Schäffner 2000: 4). Y este hecho es algo de consecuencias muy importantes que todavía no se han estudiado en profundidad: "Globalisation in the sense of homogenisation of discursive practices will therefore have profound social and cultural implications, because discourse embodies and transmits assumptions about social relations, identities and values» (Schäffner 2000: 4). En mi opinión, a través de ese lenguaje homogeneizado -mencionado por Schäffner- que ha traído consigo la globalización, las revistas femeninas y otros medios de comunicación han conseguido ir creando un ser mujer homogeneizado, mediante una semiología igualmente global e impuesta sutilmente. En todo esto, los medios de comunicación han tenido, como sabemos, un papel esencial, pero también 
la globalización del siglo XXI, porque «[g]lobalisation processes affect all areas of life, from institutions to values, and also the daily activities of individual people» (Schäffner 2000: 1), incluso sin que esas personas se percaten ni sean conscientes de esa influencia, lo cual es, lógicamente, lo más peligroso. La revolución de Internet ha hecho posible la difusión totalmente nueva de información, valores e ideales con una rapidez que nadie antes podría haber imaginado. Por eso es cada vez más fácil la homogeneización, al menos superficial. Pero lo que hay que preguntarse es quién la difunde y con qué fin. Estas van a ser preguntas que subsistirán agazapadas a lo largo de este ensayo:

[...] the media's framing (in every sense of the Word) of women in highly restricted and mostly negative ways is not simply the consequence of the idiosyncrasies of this newspaper or that TV channel or that radio station but, rather, is a global phenomenon that has endured over time and media form, and continues to do so. The type of story that most frequently features woman as a victim, usually of male sexual violence, says something profound about the role of women in society. Where are the stories of women's success in business, in politics, in education, in science? (Byerly y Ross 2006: 8)

Una manera de abordar esta cuestión de la homogeneización de la identidad femenina a través de la homogeneización del lenguaje es partir del concepto de lo «natural ${ }^{5}$ que analiza brillantemente Roland Barthes en Mitologías. Este concepto me servirá para reflexionar sobre el lenguaje utilizado en las revistas femeninas, entre otras cosas porque el propio Barthes considera éstas, las revistas femeninas, como uno de esos mitos.

\section{Lo natural}

Según Barthes, el lenguaje no refleja inocentemente la realidad sino que el sentido se va construyendo mediante lo que él llama significado de segundo nivel, que transmiten los símbolos y los objetos culturales. Mito es, para Barthes, el lenguaje de las proposiciones ideológicas. Pero lo más peligroso del mito es que todo lo relativo a él se nos impone como lógico, natural y universal. Mitologías es un libro que intenta, precisamente, desnaturalizar, romper el halo de lo «normal» y de lo «natural» (Alonso y Fernández 2006a: 206). Las revistas femeninas dicen ir dirigidas a una mujer de hoy, real, de su tiempo, y dan como natural que esa mujer desee, «lógicamente», lograr los objetivos que la revista propone. Por eso creo que las palabras de Barthes explicando en el prefacio de su libro por qué decidió escribir contra la «naturalidad» del lenguaje son aquí apropiadas: «un sentimiento de impaciencia ante lo "natural" con que la prensa, el arte, el sentido común, encubren permanentemente una realidad» (Barthes 1957/2009: 9).

Es muy interesante recordar además que en su Sistema de la moda Barthes (1967/2003) analiza años después en esa misma línea los dictámenes de la moda difundidos por las revistas femeninas. En esta obra fundamental de la semiología de los años sesenta del siglo XX, Barthes concluye que la moda no es sino un sistema de representación que da la impresión de individualidad y soberanía pero que en realidad cumple la función inconsciente de clasificación y jerarquización social: el código habla por medio de los ropajes, y, más que ser utilizados por los individuos, son los ropajes quienes utilizan a los individuos para representar un sistema de similitudes y diferencias que reproducen el lenguaje de las apariencias más allá de la historia 
(Alonso y Fernández 2006b: 16). El mito une la palabra a un determinado sentido ideológico que representa un sistema dual: por un lado un sistema denotado, es decir, que como signo hace referencia a un objeto y, por otro, es un sistema connotado, que sugiere un valor secundario, que se relaciona con otro significado (Alonso y Fernández 2006b: 24).

Un ejemplo de esta utilización del lenguaje es el discurso de los anuncios de perfumes, analizado en profundidad, entre otros, por Judith Williamson (1978) y Catherine Belsey (1980). La primera, partiendo de Barthes y Saussure, no se plantea tanto lo que significa un anuncio sino cómo significa lo que significa. La principal estrategia de un anuncio es crear semiológicamente la diferencia: sólo se anuncian artículos como perfumes, cigarrillos, cremas, que básicamente son iguales, pero que es necesario presentar, sobre todo a través de la imagen y del lenguaje, como algo que nos va a diferenciar. Por eso Williamson analiza, entre otros muchos, un anuncio de Chanel $n^{\circ} 5$ que hizo en su día la actriz francesa Catherine Deneuve (Williamson 1978). Esta actriz es parte de un sistema de signos que la caracteriza como diferente de otras actrices, y la lectora crea una asociación inconsciente entre la significación de Deneuve, que la mujer (española) asocia con elegancia, clase y glamour, y la significación del perfume. En los anuncios de perfumes se ve el sistema saussureano de diferencias literalmente en proceso de construcción. Los perfumes se diferencian entre sí por el olor, claro, pero la estrategia de su venta depende de que se asocie un determinado olor a un significado social. Por eso el lenguaje utilizado en su publicidad hace que el producto se convierta en el significante de un significado cultural e ideológico: el tipo de mujer al que se dirige un perfume de Gaultier (y las consiguientes modelos que los acompañan) no es el mismo que otro de Dior. El anuncio muestra una fotografía realista de cada tipo de mujer, y es que el realismo es plausible, no porque refleje el mundo, sino porque se construye a partir de algo que nos resulta familiar (desde el punto de vista discursivo): se construye el significado creando asociaciones entre el producto y sus significados, sobre todo porque los códigos utilizados son ya parte de nuestro conocimiento:

The plausibility of the individual signifieds is far less important to the reading process than the familiarity of the connections between the signifiers. It is the set of relationships between characters or events, or even between characters and events, which makes fantasy plausible. (Belsey 1980: 52)

La mujer se va constituyendo de una determinada manera a través de unos códigos discursivos que no son sino órdenes arbitrarios, construidos históricamente, en apariencia fijos e inmutables, normales y naturales, pero que en realidad son representaciones sesgadas por ideologías concretas, muy importantes porque aprehendemos el mundo a través de esos códigos. Y puesto que la realidad sólo puede conocerse mediante las formas que la articulan, no puede existir realidad fuera de la representación. Creo que esta idea es crucial en el tema que nos ocupa, porque enlaza directamente con otro concepto fundamental aquí, ya sugerido, como es el de la aparente naturalidad de los textos. Lo que leemos en las revistas femeninas (pero también, obviamente, en cualquier medio de comunicación) no es nunca espontáneo ni inocente, sino que responde a unas estrategias que la institución responsable del texto o el editor o jefe del periódico han decidido previamente. Es lógico que en Telva aparezca un artículo de opinión muy distinto a otro en Marie Claire sobre el mismo tema, por citar dos revistas españolas de ideología opuesta. Sin embargo, las estrate- 
gias serán iguales: ambas intentarán transmitir un mensaje «auténtico» que planteará ideas «lógicas» $\mathrm{y}$ «naturales» (en el sentido de Barthes), «cargadas de sentido común». Por lo tanto, lo importante (y muy importante a la hora de traducir) es no caer, ni con estas revistas que acabo de mencionar ni con ningún medio de comunicación de masas en general, en lo que Byerly y Ross llaman muy acertadamente «the lie of authenticity»:

The lie of authenticity that sits behind this facile and pompous claim has been constantly challenged by any number of studies that seek to understand how news really works, how decisions about content are made, how sources are identified and used, who owns the media, and so on ... There is never any acknowledgement that what we see, read, and listen to in the news is the result of myriad selection decisions that follow journalistic conventions in terms of what constitutes a "good" news story ... to understand news it is first necessary to understand the various "frames" within which news narratives are contextualized ... These frames provide an interpretive structure that enables a particular story to be described, but they are not value-free. They are, rather, ritualized ways to understand the world, of presenting a reality that excludes/includes, and that emphasizes/plays down certain facts ... The ways in which women are represented in news media send important messages to the viewing, listening, and reading publics about women's place, women's role, and women's lives. (Byerly y Ross 2006: 39-40)

Desde un sistema semiológico de segundo orden se naturalizan los conceptos, o, según demuestra Barthes en $S / Z$, texto y lector negocian una serie de asunciones ideológicas que parecen naturales pero que son en realidad «entièrement livresques». Por ejemplo, en el citado Système de la mode, el autor nos da el siguiente ejemplo: las revistas femeninas suelen decir, de la forma más natural, Este año el largo de las faldas baja hasta la rodilla; con este tipo de frases, la moda edifica un sistema muy estricto de signos y da a esos signos la apariencia de puras razones:

El signo es la unión del significante y el significado, del vestido y el mundo, del vestido y la Moda. Sin embargo, la revista no siempre ofrece ese signo de manera declarada; no dice obligatoriamente: el accesorio es el significante del significado primavera; los vestidos cortos son, este año, el signo de la moda; de forma muy distinta, dice: el accesorio hace a la primavera; este año, los vestidos se llevan cortos; a través de su retórica puede transformar la relación entre significante y significado y sustituir la pura equivalencia por la ilusión de otras relaciones (la transitividad, la finalidad, la atribución, la causalidad, etc.). En otras palabras, al tiempo que la Moda edifica un sistema muy estricto de signos, procura dar a esos signos la apariencia de puras razones; y precisamente porque la Moda es tiránica y su signo arbitrario, debe convertirlo en hecho natural o ley racional: la connotación no es gratuita; en la economía general del sistema, su función es la de restaurar una determinada ratio. (Barthes 1967/2003: 299-300)

Y precisamente porque la moda es tiránica y signo arbitrario, debe convertirse en hecho natural o ley racional. Por eso Umberto Eco, en un ensayo inspirado en Barthes, señala que

[...] basta con observar una revista de modas al comienzo de una temporada para ver que hasta las variaciones están previstas con cierta rigidez: la cintura más alta, el botón más bajo, la combinación de un zapato determinado con un tipo determinado de pantalón pueden revelarse desviaciones tan graves del uso lingüístico como el dialectalismo o el anacoluto sintáctico. (Eco 1976: 19) 
Otro ejemplo también muy significativo es el tan manido «Porque yo lo valgo» de L'Oréal: la naturalización hace pensar a la receptora que ella también lo vale (¿por qué no se lo va a merecer?) y que quizá se parezca, aun lejanamente, a la estupenda modelo del anuncio (de nuevo, ¿por qué no?): se trata, por decirlo con Barthes, de producir sentido fuera de todo contenido a partir de una paradoja semiológica por la que se intenta, por un lado, revestir de significación a lo real y constituir sistemas semiológicos fuerte y sutilmente organizados, convirtiendo las cosas en signos y lo sensible en significante (ver Munday 2004: 209), y, por otra, una vez constituidos esos sistemas, intentar enmascarar su naturaleza para volver a convertir la relación semántica en relación natural o racional.

La publicidad construye a través del lenguaje un papanatismo en el que unos deciden y otros acatan. Es un sistema complejísimo en el que se juega con la imagen y con la ilusión que todos tenemos de llegar a ser lo que nunca seremos. Pero ¿cómo resistirse? Seguiremos consumiendo porque en el fondo estamos convencidas de que nosotras lo valemos.

Es tremendo pensar que somos nuestro propio anuncio. $\mathrm{Y}$ a veces literalmente: hace unas cuantas temporadas, Moschino lanzó una serie de camisetas donde se leía Stop the Fashion System, una frase que, como ninguna, ejemplifica la anorexia del lenguaje, la bulimia del significado. Stop the Fashion System invita, paradójicamente, a comprar, a consumir los productos de un diseñador carísimo que se reía de todo el tinglado (¿y de las consumidoras?). Desconstruía desde dentro del propio sistema, pero al mismo tiempo se enriquecía con esa desconstrucción. Todos hemos visto anuncios increíbles de pócimas mágicas que consiguen que reduzcamos barriga sin esfuerzo; o ese anuncio de una crema antiarrugas que promete eliminar las marcas del paso del tiempo en dos semanas. Quiero pensar que, en el fondo, todos sabemos que no se bajan kilos sin dieta ni es posible eliminar de una forma tan natural las arrugas. Pero lo cierto es que esos productos se venden año tras año, a pesar de que los nutricionistas y los dermatólogos nos advierten contra ellos. ¿Por qué, entonces, se siguen comprando? Es el lenguaje. Sólo el lenguaje.

\section{4. ¿Qué hay de peligroso en el hecho de que la gente (no) traduzca?}

Estas cuestiones hasta aquí planteadas son siempre, sin embargo, mucho más complejas y sutiles de lo que parecen, sobre todo porque cualquier tipo de lenguaje es un ser vivo cuya utilización puede ser un acto tan alienador como liberador. Eso lo saben especialmente los traductores, que al utilizar el lenguaje sacan a la luz la posibilidad misma de llegar a universalizar y naturalizar determinados valores.

El lenguaje de las revistas femeninas tiene muy presente esta situación, pero un detalle que llama poderosamente la atención en el caso de las revistas femeninas españolas es la no traducción de ciertas palabras en los textos y anuncios que en ellas aparecen. En España, un país donde todo el mundo estudia inglés pero pocos lo hablan correctamente, hoy en día sería impensable abrir una revista como Vogue, Elle, Cosmopolitan, Woman o Marie-Claire y no encontrarse más que textos y publicidad únicamente en español. Desde la portada hasta la última página, aparecen palabras en inglés y en francés. En el número de diciembre de 2011 de Woman, por ejemplo, encontramos en la portada frases como Súper Outlets de súper marcas, Accesorios de It Girls, y en páginas interiores abundan expresiones como High class, 
chic, brit girls, hit girl, showroom, etc. Lo mismo ocurre en el número de ese mes de Telva: glamour, paillettes, antiageing, ¡too much! y otras por el estilo. Además, algunas palabras están mal escritas, como súper o antiageing, o los signos de exclamación y la puntuación mal utilizados. En revistas como Telva o Marie Claire estas palabras aparecen sobre todo en artículos relacionados con el mundo de la moda, y suelen evitarse, aunque también surgen en ocasiones, en los artículos y entrevistas más «serios», como los que las revistas dedican a temas como la salud, el trabajo o la expansión económica de determinadas empresas relacionadas con la imagen.

Esta utilización del lenguaje no es ni casual ni inocente, como podemos imaginarnos, sino que ayuda a ir construyendo ese significado secundario del que habla Barthes en El sistema de la moda. De hecho, al principio de ese libro Barthes deja claro que entiende el lenguaje de las revistas femeninas como una traducción, y no puedo estar más de acuerdo:

El objeto de análisis no es, por lo tanto, una simple nomenclatura, sino un verdadero código ... De ahí que en realidad este trabajo no verse ni sobre el vestido ni sobre el lenguaje, sino ... sobre la «traducción» del uno al otro, en tanto el primero es ya un sistema de signos ... fuera de la palabra no es posible la Moda ... Esa presencia fatal de la palabra humana no es, por supuesto, inocente ... Para obnubilar la conciencia contable del cobrador es necesario extender ante el objeto un velo de imágenes, razones, sentidos, elaborar una sustancia mediata que lo envuelva ... crear, en suma, un simulacro del objeto real ... Lo verdaderamente destacable en este imaginario constituido según una finalidad de deseo ... es que su sustancia es esencialmente inteligible: lo que suscita el deseo no es el objeto sino el nombre, lo que vende no es el sueño sino el sentido. Si eso es cierto, los innumerables objetos que pueblan y constituyen el imaginario de nuestro tiempo serán cada vez más competencia de una semántica, y la lingüística, a través de ciertos desarrollos, se convertirá, en virtud de un segundo nacimiento, en la ciencia de todos los universos imaginados. (Barthes 1967/2003: 13-14)

Con este tipo de estrategias, utilizadas por estas revistas, se pone en práctica la idea tan desarrollada desde la teoría por muchos autores, desde Foucault o Barthes y Bourdieu hasta $\mathrm{Eco}^{6}$, de que el lenguaje es más un instrumento de poder que de comunicación: en estas revistas los mensajes ponen de manifiesto el poder inherente al lenguaje mismo y también el tipo de autoridad o legitimidad que lo respalda. Así, se valen de tópicos y mitos (en el sentido barthesiano de la palabra) para vender un producto, apelando al subconsciente o a deseos inconfesables. Y evidentemente funciona: la estrategia es coherente con las imágenes y el contexto general de las revistas, que no sólo venden un producto determinado sino el halo que este trae consigo, los significados secundarios inherentes al referente en sí. Estas palabras que el traductor deja sin traducir traen consigo una importante carga de capital cultural, por utilizar la terminología de Bourdieu que refleja el habitus que se le sobreentiende al receptor, todo lo cual «permits us release from abstract binary formations of opposition -high to low, or elite to popular culture- which stand or fall on what Bourdieu socialized as “distinction"» (Lennon 2010: 29; véase también Pennycook 1997).

¿Por qué se dejan sin traducir tantas palabras? ¿Por qué, en el mundo de la moda española, si entramos en una tienda de ropa cara la dependienta nos pregunta si lo que deseamos es un blazer de color navy, y no una chaqueta de color azul marino? ¿Por qué nos venden unos shorts y no unos pantalones cortos? ¿Por qué muchísimas cadenas de ropa española anuncian la llegada de la ropa de la nueva temporada como New Collection y no Nueva colección? ¿Por qué prácticamente todas esas cadenas 
utilizan las letras S, M, L y XL para remitir a las tallas de las prendas, y no P, M, G y $\mathrm{XG}$, que son las que corresponderían a las palabras españolas? ¿Por qué se emite en las pantallas de las televisiones españolas, tanto públicas como privadas, un anuncio de perfume en el que una lánguida Kate Moss aparece hablando en inglés, sin doblar y sin siquiera subtítulos? Y la verdad es que lo que dice no es en absoluto difícil de traducir, porque el lema de la campaña de Calvin Klein, Just $B e$, no responde más que a esa metafísica de pacotilla típica de la era global del pensiero debole. Lo curioso de todo esto es que el hecho de que se vayan «colando» otras lenguas por las grietas del lenguaje es algo que en España nos parece absolutamente «natural».

A la hora de traducir ese tipo de textos el mecenas desea fervientemente que el traductor tenga en cuenta ese poder simbólico del lenguaje al que me he estado refiriendo. De ahí la petición que he mencionado al principio de este ensayo por parte de la empresa que estaba buscando un traductor de textos relacionados con moda y productos femeninos. ¿Qué pasaría si el traductor lo tradujese absolutamente todo? ¿Es lo mismo, para la receptora española del texto, leer blazer que chaqueta? Evidentemente no, porque los sinónimos completos no existen; porque las palabras no sólo significan, sino que, sobre todo, evocan. En todos estos casos, se considera que la desviación de la norma sería absurda, porque los términos no traducidos son absolutamente necesarios e inherentes a ese tipo de textos, si la traducción quiere cumplir la función que se le ha asignado. Un texto son textos, nada de lo escrito está exento de la simultaneidad de lo que le acompaña, y las palabras nunca son sólo lo que parecen, sino que traen consigo ecos, resonancias, remites, coincidencias y contradicciones (Gándara 1998: 19).

Por eso me parece fascinante investigar el caso de España y de la utilización continua del inglés. Tal vez porque, quizás inconscientemente, los españoles nos seguimos considerando una cultura débil respecto a las potencias del ámbito angloparlante, especialmente Estados Unidos, se dejan en inglés muchas palabras por varias razones posibles: para darle al producto que se está intentando vender un lustre tecnológico que avale su elevadísimo precio (y si no véase cualquier anuncio en España de productos de Estée Lauder o Christian Dior, por mencionar sólo dos marcas de cosmética en cuyos anuncios siempre encontramos palabras no traducidas) o en el caso de productos más baratos para un público adolescente, porque esos receptores se muestran sistemáticamente fascinados por cadenas de comida o marcas de ropa norteamericanas. Todos estos sentimientos de asimetría complican mucho las cosas cuando un traductor español recibe el encargo de traducir un anuncio de uno de estos productos o un texto relacionado con el mundo de la moda para una revista femenina. El habitus cambia, y a pesar de todo tal vez queramos asimilarnos a un capital cultural que globalmente se nos ofrece como natural y lógico, que «todo el mundo» desea, pero que tiene diferente valor según los diferentes contextos. Por eso Spivak advierte de que «The status of a language in the World is what one must consider when teasing out the politics of translation» (Spivak 1993/2009: 214). ¿O quizá sea porque en estos textos quien encarga la traducción piensa que el receptor no necesita/no debe entender? ¿Tal vez detrás de las palabras haya dejado de haber algo? ¿O es que es mejor que no entendamos? «Advertising may not always be directly selling a product, but they are reinforcing or constructing an image, seeking to affect people's behaviour in some way, or at least to make them stop and think» (Munday 2004: 199-200). 
Puede que hayamos alcanzado esa teoría seductora del lenguaje que Jean Baudrillard reclama en El otro por sí mismo. Desde luego, lo que sí es cierto es que el lenguaje de estas revistas está formado por esos signos despojados de sentido que el sociólogo francés reclama en De la seducción, signos que se multiplican y se hipertrofian precisamente porque ya no tienen secreto, ya no tienen crédito o tienen un crédito sin fundamento, basado en la idea naturalizada que tenemos de unos personajes, de un estatus social que suponemos poseen los demás y que asumimos como mítico. Son signos aterrorizados ante la idea de significar algo, ante la posibilidad de la inmediatez y de la aritmética lingüística. El sentido se dispersa, y el individuo asiente a mucho más de lo que cree.

La utilización del inglés o del francés en los textos de las revistas femeninas españolas, mezclando esas lenguas con el español, no tiene nada que ver, por supuesto, con la mezcla de lenguas en los llamados «hyphenated writers» (Vidal Claramonte 2007 y 2010), que crean textos híbridos en los que la utilización híbrida de lenguas mezcladas muestran la tensión entre globalización y tribalización, con una clara finalidad política y reivindicativa. En este caso, la hibridación no posee esa finalidad subversiva, sino más bien todo lo contrario. Aquí la mezcla de lenguas está relacionada con el mercantilismo, con una intención muy clara de vender más relacionada a su vez con un sentimiento de asimetría: de hecho, es realmente significativo que ni en las versiones inglesas ni francesas de las revistas femeninas más importantes internacionalmente exista (al menos en grado tan elevado) esa mezcla e interferencia de palabras en otros idiomas. En todas las revistas que he consultado en francés o en inglés no se da esa constante invasión de esas lenguas que, al parecer, los españoles relacionamos con sociedades más avanzadas tecnológicamente o con más glamour. Así las cosas, es evidente que en estos casos la (no) traducción desempeña un papel muy relevante, porque está claro que la utilización en exceso de estos términos en otras lenguas, estemos o no de acuerdo con esa estrategia, es necesaria en este contexto: funciona porque garantiza una mejor aceptación del producto.

¿Qué pasaría si un traductor decidiese no incorporar ni una sola palabra en inglés o en francés en su traducción de un artículo de moda para una revista femenina española? Sinceramente, no creo que el mecenas aceptase esa traducción, y, lo que es peor, está claro que esa traducción sería absurda actualmente porque no cumpliría la función encomendada por quien la encarga. Además, las lectoras se sentirían francamente sorprendidas por ese tipo de lenguaje, que ha dejado de ser normal (es curioso: ha dejado de ser normal leer en una revista femenina española un texto sólo en español, aun cuando la gran mayoría de lectoras, especialmente si son adolescentes, no conocen bien esas otras lenguas). El problema es realmente complejo, porque los traductores tienen que ser fieles a las intenciones de quien los contrata. Pero ¿deben plegarse a todas sus demandas? La verdad es que no creo que en este momento nadie tenga una respuesta definitiva a todas las preguntas que he ido planteando a lo largo de estas pocas páginas en relación con un tipo de traducción que se está haciendo hoy en España para unos textos que obligan al traductor a enfrentarse a muchas preguntas para las que no hay una única respuesta. Y no se trata sólo de preguntas respecto al texto original o respecto a la traducción, sino, sobre todo, preguntas sobre uno mismo, porque,

[...] translations can be read not only with reference to the originals they represent, and not only for what they say about whatever they and their originals speak about 
outside themselves. They can also be read for what they say about their individual way of re-enacting an original - and also, more generally, about the kind of re-enactment that is called translation. In this perspective, each individual rendition exhibits a particular mode of representation profiled against the ever-present possibility of alternative modes and other performances. (Hermans 2007: 69)

Actualmente el traductor sabe que traducir no es una acción inocente (como no lo es el lenguaje), que no es un ser neutro sino un sujeto que interviene activamente en la comunicación. Cada traducción revuelve al traductor, porque nunca sale incólume del proceso, porque nunca se traduce entre textos y culturas iguales ni en situaciones de simetría, porque el lenguaje y la traducción van configurando nuestras identidades (en plural):

[...] language may be one of many elements that allow us to make sense of things, of ourselves [...] Making sense of ourselves is what produces identity. If one feels that the production of identity as self-meaning, not just meaning, is as pluralized as a drop of water under a microscope, one is not always satisfied, outside of the ethicopolitical arena as such, with "generating" thoughts of one's own [...] For one of the ways to get around the confines of one's "identity" as one procedes expository prose is to work at somene else's title, as one works with language that belongs to many others. This, after all, is one of the seductions of translating. It is a simple miming of the responsibility to the trace of the other in the self. (Spivak 1993/2009: 200-201)

Por eso un autor como Appiah, tan preocupado por estas cuestiones, da en el clavo cuando asegura que traducir no puede ser buscar lo mismo sino que lo que le interesa es

[...] to explore some of the reasons why it is that this prima facie thought should be resisted: I shall argue that most of what interests us in the translations that interest us most is not meaning, in the sense that philosophy of language uses the term: in many cases $[. .$.$] getting the meaning, in this sense, right is hardly even a first step towards$ understanding. (Appiah 1993/2000: 418)

Ahí está la clave, darse cuenta de que llegar al significado no significa necesariamente entenderlo, que el significado no es lineal ni monocromático, sino plural, heteroglósico y cargado de matices. Como bien dice Appiah, llegar al significado no es suficiente. El traductor sabe que debe re-presentar lo real y sus grietas, mundos propios y ajenos, visiones polimorfas a través de signos uniformes; sabe que la traducción no es reproducción fiel ni neutral sino un acto deliberado de posicionamiento ideológico (Tymozcko 2003). Así, desde esta perspectiva, traducir es plantearse «the vagaries and vicisitudes of the exercise of power in a society, and what the excercise of power means in terms of the production of culture, of which the production of translations is a part» (Bassnett y Lefevere 1990: 5). La traducción en el siglo XXI es una condición permanente del ser humano que se refleja en una práctica discursiva que revela los múltiples signos de la polivalencia con la que están construidas las culturas (Gentzler 2008).

No ha sido mi intención, ni mucho menos, ofrecer en este artículo la solución a un problema de traducción. Pero sí creo que el mero hecho de llamar la atención sobre esta cuestión es ya un primer paso para al menos pensar en lo que puede haber detrás. Porque la primera reacción ante estos textos es decir que esa utilización de otras lenguas, especialmente del inglés, es normal, pero también se puede concluir 
que esa normalidad y naturalidad responde a lo que ideológicamente hay detrás de esos términos, tal y como nos advirtiera Roland Barthes. Aún queda mucho por hacer en este campo dentro de los estudios de traducción, entre otras cosas porque, por un lado, y aunque se ha avanzado muchísimo en pocos años, es todavía un área de conocimiento joven, y son todavía muchos los frentes abiertos; y, por otro, porque tal vez no haya una respuesta definitiva para este tipo de problemas ni una solución mágica. De lo que sí estoy convencida es de que un primer paso fundamental es hacer conscientes a las generaciones futuras de traductores de que esos problemas están ahí, de que deben localizarlos, analizarlos, saber qué implicaciones, connotaciones y consecuencias tiene leer en la portada de una revista Escapadas low chic, Look working o un vestido vintage (frases que naturalmente desprenden mucho más glamour que si hubiesen aparecido totalmente traducidas: Escapadas baratas, qué me pongo para ir a trabajar cada día o un vestido de temporadas pasadas); Gafas tamaño oversize, Elige el chic más minimal, Planes non stop de sol a sol o Suero antimanchas Even Better Clinical Dark Spot Corrector. En este último caso, ¿aceptaría la marca Clinique la traducción total al español del anuncio de este producto? ¿Serían los mismos los resultados e impacto de esa publicidad? La respuesta es evidente: la no traducción contribuye a la venta de esos productos por los significados de segundo nivel que esas no traducciones traen consigo en el contexto del receptor y de la cultura meta en general.

En este sentido, volviendo a donde habíamos comenzado, cabe terminar con el siguiente comentario de Foucault: los discursos, al igual que los silencios, no están de una vez por todas sometidos al poder o levantados contra él. Hay que admitir un juego complejo e inestable donde el discurso puede, a la vez, ser instrumento y efecto del poder, pero también obstáculo, tope, punto de resistencia y de partida para una estrategia opuesta. Tal vez sea en esa difícil conjunción donde haya que buscar el comienzo del camino que hoy, en la era global, debemos emprender los traductores, enfrentándonos a retos tan nuevos como en continua transformación, igual que la comunicación, cada vez más rápida y menos profunda, entre las personas.

\section{NOTAS}

* $\quad$ Este artículo es parte del proyecto de investigación FFI2009-10697 financiado por el Ministerio de Ciencia y Tecnología titulado Traducción y discursos políticos: conflictos éticos e ideológicos en la era de la inmigración y la globalización.

1. Hay que tener muy en cuenta, sin embargo, que esta autora ha cambiado de opinión sobre este punto en publicaciones posteriores (véase McRobbie 2004; 2005; 2006).

McRobbie, Angela (2004): The rise and rise of porn chic. The Times higher educational supplement. 2 January.

McRobise, Angela (2005): Cutting girls down to Victoria Beckham's size. The Times higher educational supplement. 14 October.

2. «Magazines aimed at women, and increasingly those for men, contain all kinds of advice on how to live, look and interact. Even if we only read these items in an ironic state of mind, it must all sink in somewhere ... Images of 'attractive people' abound. This may have absolutely no influence on how we rate our own appearance, and that of others -but that's improbable» (Gauntlett 2008: 3).

3. En el ensayo «The Culture Industry: Enlightenment as Mass Deception,» contenido en el conocido libro que escribió con Horkheimer en 1947 titulado Dialéctica de la Ilustración, Adorno asegura que la cultura no es más que una industria, y que nos viene impuesta desde arriba. Estos autores advierten contra la ilusión de que al zambullirnos en el mundo de los medios de comunicación pensemos que podemos elegir (qué programa escuchar o ver, qué revista leer, etc.): no es así, la posibilidad de hacer una elección libre es una ilusión porque nuestro consumo «merely fosters the 
circle of manipulation and retroactive need in which the unity of the system grows ever stronger ... The customer is not the king, as the culture industry world have us relieve, not its subject but its object» (Adorno 1991: 121, 85).

4. Bonet, Joana (2010): Editorial. Marie Claire España. 2010(10):2.

5. No me resisto a mencionar, aun de pasada, porque sería un concepto que merecería ser desarrollado mucho más detalladamente en otro lugar, que la idea de la naturalización de Barthes podría relacionarse con Antonio Gramsci, cuando éste destaca que quien ostenta el poder puede hacerlo con más facilidad si convence a los subalternos (y utilizo aquí este término en el sentido de Gayatri Spivak) de que lo que él dice responde al «sentido común», lo que sin duda podría aplicarse a los textos que estamos analizando aquí. Algo parecido sugiere el concepto de «interpelación» de Althusser, que intenta demostrar «how an individual's identity or sense of self is absorbed into and, indeed, produced by - the dominant ideologies within a society» (Gauntlett 2008: 30-31). El concepto de Althusser es sin duda de fácil aplicación en el análisis de los textos de las revistas femeninas, tal y como han demostrado ya algunos estudios: «Interpellation occurs when a person connects with a media text: when we enjoy a magazine or TV show, for example, this uncritical consumption jeans that the text has interpellated us into a certain set of assumptions, and caused us to tacitly accept a particular approach to the world. This can be a fruitful notion, then: it could be said, for example, that lifestyle magazines use glamour, humour and attractive photography to seduce (interpellate) readers into a particular worldview» (Gauntlett 2008: 31)

6. Es interesante en este sentido el artículo que Eco (1977/1986) dedica a analizar las reflexiones de Barthes sobre lenguaje y poder partiendo de Foucault.

\section{REFERENCIAS}

Adorno, Theodor W. (1991): The culture industry: Selected essays on mass culture. London: Routledge.

Alonso, Luis Enrique y Fernández, Carlos (2006a): Presentación. Empiria. Revista de metodología de ciencias sociales. 11:205-221.

Alonso, Luis Enrique y Fernández, Carlos (2006b): Roland Barthes y el análisis del discurso, Empiria. Revista de metodología de ciencias sociales. 12:11-35.

Barthes, Roland (1957/2009): Mitologías. (Traducido por Héctor Schmucler) Madrid: Siglo XXI. Barthes, Roland (1967/2003): El sistema de la moda y otros escritos. (Traducido por Carles Roche) Barcelona: Paidós.

BARthes, Roland (1985/1990): La aventura semiológica. (Traducido por Ramón AlCALde) Barcelona: Paidós.

Bassnett, Susan y Lefevere, André, eds. (1990): Translation, history and culture. London: Pinter.

Belsey, Catherine (1980): Critical Practice. New York: Methuen.

Bourdieu, Pierre (1991): Language and symbolic power. (Traducido por Gino Raymond y Matthew Adamson) Harvard: Harvard University Press.

Byerly, Carolyn M. y Ross, Karen (2006): Women \& media. A critical introduction. Oxford: Blackwell.

Cronin, Michael (2003): Translation and globalization. London: Routledge.

Eco, Umberto (1976): El hábito hace al monje. (Traducido por Carlos Manzano) In: Umberto Eco. Psicología del vestir. Barcelona: Lumen.

Eco, Umberto (1977/1986): La lengua, el poder, la fuerza. En: Umberto Eco. La estrategia de la ilusión. (Traducido por Edgardo Oviedo) Barcelona: Lumen, 336-354.

Eco, Umberto (1984/1990): Semiótica y filosofía del lenguaje. (Traducido por Roberto PelleRey) Barcelona: Lumen.

FraZer, Elizabeth (1987): Teenage girls reading Jackie. Media, culture and society. 9:407-425.

Foucault, Michel (1970): El orden del discurso. Barcelona: Tusquets.

Friedan, Betty (1963): The feminine mystique. London: Penguin.

Gallego Ayala, Juana (1990): Mujeres de papel. De ¡Hola! A Vogue. Barcelona: Icaria.

GÁndARA, Alejandro (1998): Las primeras palabras de la creación. Barcelona: Anagrama.

Gauntlett, David (2008): Media, gender and identity. London/New York: Routledge. 
GeNTZler, Edwin (2008): Translation and identity in the Americas. New directions in translation theory. London/New York: Routledge.

Hermans, Theo (2007): Translation, irritation and resonance. In: Michaela Wolf y Alexandra FUKARI, eds. Constructing a sociology of translation. New York/Amsterdam: John Benjamins.

Hermes, Joke (1995): Reading women's magazines: An Analysis of everyday media use. Cambridge: Polity.

Hinojosa Mellado, Ma Paz (2007): La persuasión en la prensa femenina. Madrid: Visión.

Lallana, Fernando (2000): Tipografía y diseño. Madrid: Síntesis.

Lennon, Brian (2010): In Babel's shadow. Multilingual literatures, monolingual states. Minneapolis/London: University of Minnesota Press.

Lipovetsky, Gilles (1997/1999): La tercera mujer. (Traducido por Rosa Alapont). Barcelona: Anagrama.

Martín Aguado, José A. y Armentia Vizuete, José I. (1995): Tecnología de la información escrita. Madrid: Síntesis.

McCracken, Ellen (1993): Decoding women's magazines. Basingstoke: Macmillan.

McRoвbie, Angela (1999): In the culture society: Art, fashion and popular music. London: Routledge.

McRobiie, Angela (2006): Post-feminism and popular culture: Bridget Jones and the new gender regime. En: James Curran y David Morley, eds. Media and cultural theory. London: Routledge.

Munday, Jeremy (2004): Advertising: Some challenges to translation theory. The Translator. 10(2):199-219.

Pendones de Pedro, Covadonga (1999): Estrategias discursivas en las revistas femeninas. En: J. Garrido, ed. La lengua y los medios de comunicación. Actas del Congreso Internacional de la Universidad Complutense. Madrid: Universidad Complutense, 311-322.

Pennycook, Alastair (1997): English and capital: Some thoughts. The Language Teacher. 27(10):29-34.

Phillips, Barbara (1978): Magazines' heroines: Is Ms. just another member of the family circle? En: Gaye Tuchman, Arlene K. Daniels y James Benét, eds. Hearth and home: Images of women in the mass media. New York: Oxford University Press, 25-42.

PotTer, Jonathan (1996/2008): Representing reality. Discourse, rhetoric and social construction. London: Sage.

RADNER, Hilary (1995): Shopping around: Feminine culture and the pursuit of pleasure. London/ New York: Routledge.

SChäffner, Christina, ed. (2000): Translation in the global village. Clevedon: Multilingual Matters.

Seoane, Ma Cruz y Sáiz, Ma Dolores (1988): Historia del periodismo en España. Vol. 3, El siglo $X X$. Madrid: Alianza.

SpIVAK, Gayatri Chakravorty (1993/2009): Outside in the teaching machine. New York: Routledge.

Stoll, Pamela (1994): El discurso de la prensa femenina. Análisis de los actos de habla en titulares de revistas femeninas británicas. Alicante: Universidad de Alicante.

STOLL, Pamela (1997): Speech acts and conversation: The interactional development of speech act theory. Pragmalingüística. 3-4:465-475.

Tyмоzско, Maria (2003): Ideology and the Position of the Translator: In What Sense is a Translator 'In Between'? In: María Calzada Pérez, ed. A Propos of Ideology: Translation Studies on Ideology - Ideologies in Translation Studies. Manchester: St. Jerome Publishing, 181-201.

Vidal Claramonte, M. Carmen África (2007): Traducir entre culturas. Frankfurt: Peter Lang. Vidal Claramonte, M. Carmen África (2010): Traducción y asimetría. Frankfurt: Peter Lang. Williamson, Judith (1978): Decoding advertisements: Ideology and meaning in advertising. London: Marion Boyars.

Winship, Janice (1987): Inside women's magazines. London: Pandora. 